\title{
Regulation of Ustilago maydis Dimorphism, Sporulation, and Pathogenic Development by a Transcription Factor with a Highly Conserved APSES Domain
}

\author{
María D. García-Pedrajas, ${ }^{1,2}$ Lourdes Baeza-Montañez, ${ }^{2}$ and Scott E. Gold ${ }^{1}$ \\ 'Department of Plant Pathology, University of Georgia, Athens 30602-7274, U.S.A.; 'Estación Experimental 'La Mayora', \\ CSIC, 29760 Algarrobo-Costa, Málaga, Spain
}

Submitted 16 June 2009. Accepted 8 October 2009.

In Ustilago maydis, the causal agent of corn smut, the morphological transition from yeast to filamentous growth is inextricably linked to pathogenicity; budding haploid cells are saprobic and, upon mating of compatible strains, the fungus converts to dikaryotic filamentous growth and obligate parasitism. The filamentous dikaryon proliferates in the host plant, inducing tumor formation and undergoing additional morphological changes that eventually result in the production of melanized diploid teliospores. In an attempt to identify new trans-acting factors that regulate morphogenesis in $U$. maydis, we searched for the presence of common binding sequences in the promoter region of a set of 37 genes downregulated in the filamentous form. Putative cis-acting regulatory sequences fitting the consensus binding site for the Aspergillus nidulans transcription factor StuA were identified in 13 of these genes. StuA is a member of the APSES transcription factors which contain a highly conserved DNA-binding domain with a basic helix-loop-helix (bHLH)-like structure. This class of proteins comprises critical regulators of developmental processes in ascomycete fungi such as dimorphic growth, mating, and sporulation but has not been studied in any fungus of the phylum Basidiomycota. A search for StuA orthologs in the $U$. maydis genome identified a single closely related protein that we designated Ust1. Deletion of ust1 in budding haploid wild-type and solopathogenic strains led to filamentous growth and abolished mating, gall induction, and, consequently, in planta teliosporogenesis. Furthermore, cultures of ust1 null mutants produced abundant thick-walled, highly pigmented cells resembling teliospores which are normally produced only in planta. We showed that ssp1, a gene highly induced in teliospores produced in the host, is also abundantly expressed in cultures of $u$ st 1 null mutants containing these pigmented cells. Our results are consistent with a major role for $u s t 1$ in regulating dimorphism, virulence, and the sporulation program in $U$. maydis.

In the corn smut fungus Ustilago maydis, morphological transitions are central to completion of the life and disease cycles. A switch between yeast and filamentous growth forms is critical for pathogenicity. Haploid wild-type strains grow as budding yeasts and are saprobic. Upon mating of compatible haploid strains, a filamentous dikaryon is produced and the fungus is converted to obligate parasitism; it can develop and complete its life cycle only in planta. During pathogenic devel-

Corresponding author: Scott E. Gold; E-mail: sgold@uga.edu opment, the fungus undergoes morphological changes associated with colonization of the host environment and the final production of diploid spores. These changes involve the formation of rudimentary appressoria prior to penetration of host tissue (Snetselaar and Mims 1992). The dikaryon then colonizes the plant, ramifying intra and intercellularly, and induces the formation of host tumors (Christensen 1963; Callow and Ling 1973; Luttrell 1987; Snetselaar and Mims 1994; Banuett and Herskowitz 1996). Within these tumors, a switch from vegetative to sporogenous hyphae occurs; karyogamy, hyphal fragmentation, and deposition of a thick melanized wall leads to production of diploid teliospores (Snetselaar and Mims 1994; Banuett and Herskowitz 1996). The morphological transitions that the fungal cells undergo must be accurately regulated in order to achieve successful infection and completion of the life cycle; many mutant strains with morphological alterations are either nonpathogenic or arrest at different stages of pathogenic development. Therefore, characterization of the molecular mechanisms that control morphogenesis is critical to fully understand U. maydis pathogenicity.

Mating is inextricably linked to the dimorphic switch and pathogenic development in this species. Mating is governed by the $a$ and $b$ mating-type genes. Cell fusion is controlled by the $a$ locus, which encodes pheromones and pheromone receptors similar to those of yeast (Bölker et al. 1992; Spellig et al. 1994), and which have two alternative forms: $a 1$ and $a 2$. Two haploid strains are compatible to mate only if they carry different alleles at the $a$ locus. Once cell fusion has taken place, heterozygosity at the $b$ locus is required for dikaryon stability and for pathogenicity. This locus is multiallelic and encodes two homeodomain-containing proteins that, after cell fusion, interact to produce a heterodimeric complex only when derived from different alleles (Gillissen et al. 1992; Yee and Kronstad 1993, 1998; Kamper et al. 1995). Two major conserved signaling pathways are involved in transmitting the pheromone signal and regulating dimorphism and pathogenicity, a mitogenactivated protein kinase (MAPK) cascade (Mayorga and Gold 1999; Müller et al. 1999; Andrews et al. 2000) and the cAMP pathway (Barrett et al. 1993; Gold et al. 1994, Gold et al. 1997; Durrenberger et al. 1998; Krüger et al. 2000). Activation of both pathways is required for efficient mating while, after cell fusion, the core components of these pathways play additional key roles in pathogenicity (Brefort et al. 2009).

Transcription factors are key downstream targets in signal transduction pathways; coordinated activation or repression of sets of specific genes will determine the final developmental output in response to the input signal (Levine and Davidson 2005). Therefore, the identification of these trans-acting ele- 
ments, their target genes, and the way in which they coordinate their functions is of considerable interest. In $U$. maydis, a highmobility-group (HMG) family transcription factor designated Prf1 was identified as a key downstream node in which both the MAPK cascade and the cAMP signaling pathways converge. The Prf1 protein contains putative phosphorylation sites for a MAPK and for the cAMP-dependent protein kinase (PKA) (Kahmann et al. 1999; Müller et al. 1999) and controls the expression of the $a$ and $b$ loci, among other target genes, thus connecting the pheromone response pathway to the expression of the $b$ locus which, in turn, regulates the expression of virulence genes (Hartmann et al. 1996). Differential phosphorylation by PKA or MAPK allows Prf1 to discriminate promoters (Kaffarnik et al. 2003). Brefort and associates (2005) identified another HMG transcription factor, designated Rop1, as a direct regulator of prfl expression. Surprisingly, deletion of this regulatory protein severely impaired mating and filamentous growth in vitro but not in planta (Brefort et al. 2005). A few other regulatory proteins playing roles in morphogenesis have been identified in $U$. maydis. These include Rum1 (Quadbeck-Seeger et al. 2000) and Sql1 (Loubradou et al. 2001). The former is required for teliospore development and serves as a repressor of filament-upregulated genes during budding growth, whereas Sq11, a protein containing a domain also found in the Saccharomyces cerevisiae transcriptional repressor Ssn6p, plays an antagonistic role to cAMP by repressing cAMP-regulated genes (Loubradou et al. 2001). In addition, $\mathrm{Hgl1}$, which regulates filamentous growth and teliospore maturation, presumably as a downstream effector of the cAMP pathway, may also function as a trans-acting factor (Durrenberger et al. 2001). The gene fuz1, whose mutation arrests sporogenesis in planta at the stage of hyphal fragmentation (Banuett and Herskowitz 1996), was recently cloned and shown to encode an MYND Zn-finger-domain protein (Chew et al. 2008). Nevertheless, our current understanding of the complex regulatory protein networks that control the major developmental pathways is still very incomplete in $U$. maydis.

Morphological transitions between modes of growth are not unique to $U$. maydis but, rather, are common in the life cycles of fungi, including saprobes and plant and animal pathogens. Studies in different fungi have revealed that the two regulatory pathways we have described for $U$. maydis, MAPK cascades and the cAMP signaling pathway, are broadly conserved signal transduction pathways that control fungal differentiation processes in divergent species (Lengeler et al. 2000). Because of this broad conservation of components, comparison with similar processes in other fungi can help to further characterize the molecular mechanisms regulating morphogenesis in $U$. maydis. The most common human fungal pathogen, Candida albicans, is known to reversibly switch from budding yeast to pseudohyphal or true filamentous growth in response to environmental stimuli, a property that has been associated with virulence (Lo et al. 1997; Liu 2002). The cAMP pathway regulates this transition via the transcription factor Efg1 (Lo et al. 1997; Stoldt et al. 1997; Braun and Johnson 2000; Tebarth et al. 2003). Efg1 belongs to a class of regulatory proteins that contain a basic helix-loop-helix (bHLH)-like DNA-binding structure, termed the APSES domain. There are two proteins in $S$. cerevisiae, Sok2 and Phd1, with an APSES domain highly similar to that of Efg1. Interestingly, these two proteins are major players in the dimorphic transition that diploid cells of $S$. cerevisiae undergo in response to nitrogen starvation, referred to as pseudohyphal differentiation (Gimeno and Fink 1994; Ward et al. 1995). The Aspergillus nidulans APSES protein, StuA, was the first transcription factor identified in this class and is required for conidiophore morphogenesis (Miller et al. 1992) and to initiate the sexual reproductive cycle (Clutterbuck
1969). stuA mutant conidiophores lack the intermediate uninuclear cell types, the metulae and phialides. In the wild-type conidiophore, the metulae are produced by a process of budding from a multinucleate vesicle formed at the tip of an aerial stalk, and the phialides bud from the metulae (Adams et al. 1998). An APSES transcription factor in Neurospora crassa, Asm-1, is a functional analogue of StuA because it regulates both asexual and sexual sporulation (Aramayo et al. 1996). Although it appears that APSES proteins from S. cerevisiae and C. albicans function in developmental pathways distinctive from that of StuA in A. nidulans, one feature that these pathways have in common is that they involve bud-hypha interconversions. Although the number of fungal species in which this class of regulatory proteins have been characterized is expanding, now including a number of animal and plant pathogens (Ohara and Tsuge 2004; Tong et al. 2007; Wang and Szaniszlo 2007), their role in the Basidiomycota has not been determined.

The objective of this work was to identify APSES transcription factors in $U$. maydis and characterize their roles in morphogenesis and pathogenicity. We became interested in this type of regulatory protein when attempting to identify mechanisms of co-regulation of a set of genes identified as differentially expressed in the dimorphic phases (García-Pedrajas and Gold 2004). Analysis of their putative promoter regions in search of common cis-acting binding sequences identified the response element for the A. nidulans transcription factor StuA in 13 of 37 of them. This observation, together with the known roles of APSES proteins in regulating morphogenesis, most remarkably transitions to or from budding modes of growth, led us to hypothesize that an APSES transcription factor might play a key role in yeast-hypha transitions in U. maydis. Using the APSES domain of StuA to search the $U$. maydis genome database, we identified a single gene encoding a protein containing an APSES domain highly similar to that of Phd1, Sok2, StuA, Efg1, and Asm-1. We named this gene ust1 (for Ustilago $s t u A$ orthology). In the work reported here, we functionally characterize ust 1 and show that it plays a critical role in morphogenesis and disease development. Mutant analysis of this gene indicates that, like APSES proteins from ascomycete fungi, the ust 1 product plays a critical role in yeast-hypha transitions as well as in mating and spore development. Our data also indicate that Ust1 is a critical virulence factor.

\section{RESULTS}

\section{Identification of a transcription factor containing a bHLH-like APSES motif in $\boldsymbol{U}$. maydis.}

In an effort to identify new regulators of morphogenesis in $U$. maydis, we searched for common putative regulatory sequences in the $1-\mathrm{kb} 5^{\prime}$ of the start codon of a set of 37 genes previously identified as downregulated in filamentous cells (García-Pedrajas and Gold 2004). In 13 of these genes, we identified a sequence identical to the $A$. nidulans transcription factor StuA response element (StRE), ${ }_{\mathrm{A}} / \mathrm{CGCG}_{\mathrm{T}}^{\mathrm{T}} / \mathrm{N}_{\mathrm{A}}^{\mathrm{A}} / \mathrm{C}$ (Dutton et al. 1997). StuA is a founding member of the APSES transcription factors which are key regulators of fungal development. The StuA APSES domain bHLH-like structure responsible for StRE binding (Dutton et al. 1997) is conserved throughout this class of regulatory proteins and, therefore, other members likely bind similar sequences.

Database searches revealed that 1 of the 13 StRE-containing genes downregulated in filaments (accession no. CF541439) (García-Pedrajas and Gold 2004) shared significant similarity with a family of small proteins encoded by developmentally regulated genes, including Wh11p from $C$. albicans (Srikantha and Soll 1993; Srikantha et al. 1997) and Awh11p from A. nidulans (Dutton et al. 1997). This gene is annotated in the $U$. 
maydis genome as hypothetical protein UM00205 and encodes a putative 80 -amino-acid protein that shares 26.8 to $27.9 \%$ identity with Wh11p and Awh11p, respectively. An alignment of these three proteins is shown in Figure 1. Interestingly, awh11 expression is directly controlled by StuA, which was shown to specifically bind a region of the awh11 promoter that contains two StREs (Dutton et al. 1997).

These data, taken together, led us to postulate that a transcription factor in the StuA family might function in morphogenetic transitions in $U$. maydis by regulating dimorphismrelated gene expression. Therefore, the amino acid sequence of the APSES domain of $A$. nidulans StuA was used in a proteinprotein blast search at the MIPS Ustilago maydis DataBase (MUMDB), which led to the identification of a single protein with a highly similar motif, UM15042.

UM15042 was composed of two parts located on adjacent contigs 1.63 and 1.64 that were initially wrongly annotated as two different proteins, UM11140 and UM11888. To fully confirm the sequence of this putative APSES protein in $U$. maydis, the full-length cDNA sequence of its encoding gene was determined by using rapid amplification of cDNA ends (RACE) technology. Primers were designed to amplify two overlapping fragments containing the $5^{\prime}$ and $3^{\prime}$ ends of the cDNA. Amplification of the $3^{\prime}$ end produced two bands of approximately 1.5 and $1.2 \mathrm{~kb}$ that were cloned and sequenced. Sequencing of the $1.5-\mathrm{kb}$ band identified a putative polyadenylation site 369 bases after the stop codon and confirmed the absence of introns. Sequencing of the $1.2-\mathrm{kb}$ band appeared to indicate the presence of a polyadenylated tail two nucleotides after the stop codon. However, this polyadenylation was considered false because there are nine A residues in the genomic sequence in that position that may have promoted annealing with the oligo dT primer during amplification. Northern blot hybridization showed the presence of a single $u$ st 1 transcript band of approximately $3 \mathrm{~kb}$ (see below), corroborating the above interpretation of the $1.2-\mathrm{kb}$ polymerase chain reaction (PCR) band as spurious. Amplification of the $5^{\prime}$ end produced a more smeared product but two bands of approximately 1.8 and $1.0 \mathrm{~kb}$ were clearly visible. These bands were purified from the gel, cloned, and sequenced. Sequencing of several clones of the $1.8-\mathrm{kb}$ band confirmed absence of introns and revealed that the transcript's $5^{\prime}$ end is found at positions $-770 \mathrm{bp}$ (one clone) and $-781 \mathrm{bp}$ (two clones) of the start codon of the open reading frame (ORF), indicating several possible close transcriptional start sites, as is sometimes encountered (Sonneborn et al. 2000; Tebarth et al. 2003). In contrast, the 1.0-kb amplicon was unrelated to the gene of interest (not shown). In summary, assembling the sequence of both the 5' and $3^{\prime}$ cDNA fragments, a transcript size of approximately $3 \mathrm{~kb}$ was estimated for this gene encoding a putative APSES transcription factor, which we named ust 1 , with a 1,875-bp ORF, a 5' untranslated region of approximately 800 bases, and a putative polyadenylation site 369 bases after the stop codon. Comparison of the amino acid sequences of Ust1 and UM15042 showed that, although they were very similar, the latter contained a number of errors. This sequence has now been corrected at MUMDB.

Ust1 shared similarity with other APSES proteins such as the well-characterized $C$. albicans Efg1, A. nidulans StuA, and $N$. crassa Asm1, which were 24.5, 23.5, and $23.1 \%$ identical to Ust1, respectively. The identity was very high in an area of 97 amino acids composing the APSES domain; the Ust1 APSES domain is $72.2,72.2$, and $70.1 \%$ identical to that of StuA, Asm1, and Efg1, respectively. Ust1 was most similar (91\% identical APSES domains) to an APSES transcription factor identified in the recently sequenced genome of Malassezia globosa (Xu et al. 2007). This fungal species is found in the skin of warm-blooded animals and it is phylogenetically closely related to $U$. maydis. An alignment of the APSES domain of Ust1 and that of the closely related ortholog in $M$. globosa and other APSES transcription factors, including the well characterized Asm-1, Phd1, Sock2, Efg1, and StuA, is shown in Figure 2.

Two other $U$. maydis proteins, UM05338 and UM06196, contained limited but significant similarity with the APSES domain of StuA (Fig. 2). However, examination of the conserved domains of these two proteins showed that they were more closely related to another class of bHLH-containing regulatory proteins involved in cell cycle regulation, typified by $S$. cerevisiae Swi4p and Mbp1p (Wittenberg and Reed 2005). Therefore, we identified Ust 1 as the sole most probable StuA ortholog in U. maydis.

\section{Mutant analysis reveals a critical role for Ust1 in regulating cell morphology.}

To study the role of this newly identified transcription factor in $U$. maydis, a mutant allele was generated in which the entire ORF was replaced by a carboxin resistance $(c b x R)$ marker. This mutant allele was used to transform the sequenced haploid wild-type strain 1/2 (same as strain 521) (Kronstad and Leong 1989) and the near-isogenic strain $2 / 9$ (Gold et al. 1997). Transformants with wild-type appearance and others very dark in color, appeared on the plates. Seventeen transformants in total representing both types were transferred to potato dextrose agar (PDA) with carboxin. All seven dark transformants transferred grew more slowly and presented a dry-looking colony surface, unlike the 10 wild-type-looking ones, which were cream colored and had wild-type moist surfaces (data not shown). PCR analysis showed a perfect correlation between slow growth, dark color, and dry colony surfaces, and replacement of $u s t 1$ by the deletion construct; in contrast, all transformants with wild-type appearance were shown to still contain a copy of the ustl ORF (data not shown). Gene ustl was also deleted in the solopathogenic haploid strain SG200 using a second deletion allele we generated containing a hygromycin resistance $($ hygR) cassette as the selectable marker. Again, dark slow-growth transformants and others with wild-type phenotype were obtained, and the absence of the ust 1 ORF confirmed in the former by PCR analysis. Absence of ustl ORF was further confirmed in haploid strains $14 / 25$ and 14/26 and solo-



Fig. 1. Alignment of the amino acid sequence of UM00205 (García-Pedrajas and Gold 2004) and members of a family of small proteins. Candida albicans Wh11 (Srikantha and Soll 1993) and Aspergillus nidulans Awh11 (Dutton et al. 1997) are encoded by developmentally regulated genes. Expression of awh11 is directly regulated by StuA. 
pathogenic strain 14/27 (Table 1) by Northern blot hybridization (Fig. 3), and they were selected for further characterization. The typical phenotype of $\Delta u s t l$ haploid strains grown on solid medium is shown in Figure 4A. Compare the dark, filamentous looking surface of these colonies with that of wildtype colonies (Fig. 4B). Microscopic inspection of liquid-grown mutant cells showed that they grew filamentously with areas devoid of cytoplasm (Fig. 4C). Additionally, rounded cells with highly pigmented thick cell walls were observed (Fig. 4D). The number of these structures increased over time and they appear to be responsible for the very dark color of colonies and liquid cultures. A closely similar phenotype was observed in the solopathogenic haploid strain deleted for ustl (data not shown).

Table 1. Strains of Ustilago maydis used in this study

\begin{tabular}{|c|c|c|}
\hline Strain & Relevant genotype & Source \\
\hline $1 / 2(521)^{\mathrm{a}}$ & $a 1 b 1$ & Kronstad and Leong 1989 \\
\hline $1 / 9$ & alb1 uac1::ble & Gold et al. 1994 \\
\hline $1 / 68$ & alb1 ubc1::hyg & Gold et al. 1994 \\
\hline $2 / 9$ & $\begin{array}{l}a 2 b 2(\mathrm{BX} 7 \mathrm{~A} 22 \text {, near isogenic } \\
\text { to } 1 / 2)\end{array}$ & Gold et al. 1997 \\
\hline d132 & Diploid (a1a2 b1b2) & Kronstad and Leong 1989 \\
\hline SG200 & al:mfa2 bE1bW2 & Müller et al. 1999 \\
\hline $14 / 25$ & albl $\Delta u s t 1$ & This study \\
\hline $14 / 26$ & $a 2 b 2 \Delta u s t 1$ & This study \\
\hline $14 / 27$ & SG200 $\Delta u s t 1$ & This study \\
\hline $14 / 28$ & d132 $\Delta$ ust $1 /+$ & This study \\
\hline $14 / 29$ & $\mathrm{~d} 132 \Delta u s t 1 / \Delta u s t 1$ & This study \\
\hline
\end{tabular}

${ }^{\text {a }}$ Strain $1 / 2$ is strain 521 , the sequenced strain of $U$. maydis.
Due to the presence of large numbers of darkly pigmented structures at least superficially resembling teliospores in $\Delta u s t l$ strains, we hypothesized that downregulation of ustl might be important to induce teliospore formation. Teliospores produced

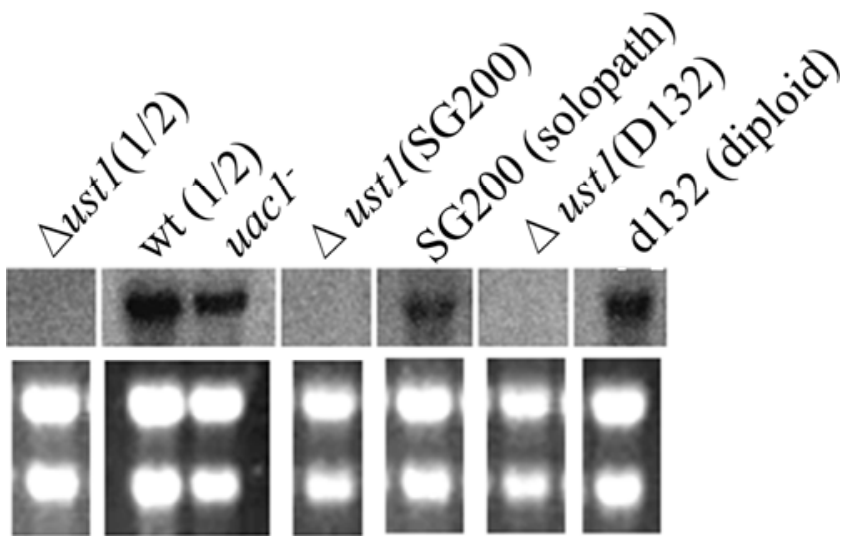

Fig. 3. Expression of $u s t 1$ in several different genetic backgrounds. Strains listed were grown for $24 \mathrm{~h}$ in potato dextrose broth prior to total RNA extraction, except the ust 1 null mutants that were grown for $48 \mathrm{~h}$. The latter were included in this study to corroborate the absence of the ust 1 transcript. A fragment of approximately $1.5 \mathrm{~kb}$ of the $u s t l$ open reading frame (from position 172 through 1716) was used as a probe. Strains are as follows: 14/25 (lane1), 1/2 (lane 2), 1/9 (lane 3), 14/27 (lane 4), 7/20 (lane 5), 14/29 (lane 6), and 2/21 (lane 7). The bottom panel shows rRNA for loading control.

\begin{tabular}{lr} 
Ust1 & 233 \\
\hline M.g1 & 218 \\
StuA & 129 \\
Efg1 & 204 \\
Asm1 & 116 \\
Phd1 & 186 \\
Sok2 & 414 \\
Mstu1 & 109 \\
P.ma & 128 \\
UM05338 & 164 \\
UM06196 & 7 \\
Swi4 & 38 \\
Mbp1 & 05
\end{tabular}



\begin{tabular}{ll} 
Ust1 & 286 \\
\hline M.g1 & 271 \\
StuA & 182 \\
Efg1 & 257 \\
Asm1 & 169 \\
Phd1 & 236 \\
Sok2 & 467 \\
Mstu1 & 162 \\
P.ma & 181 \\
UM05338 & 217 \\
UM06196 & 60 \\
Swi4 & 88 \\
Mbp1 & 58
\end{tabular}

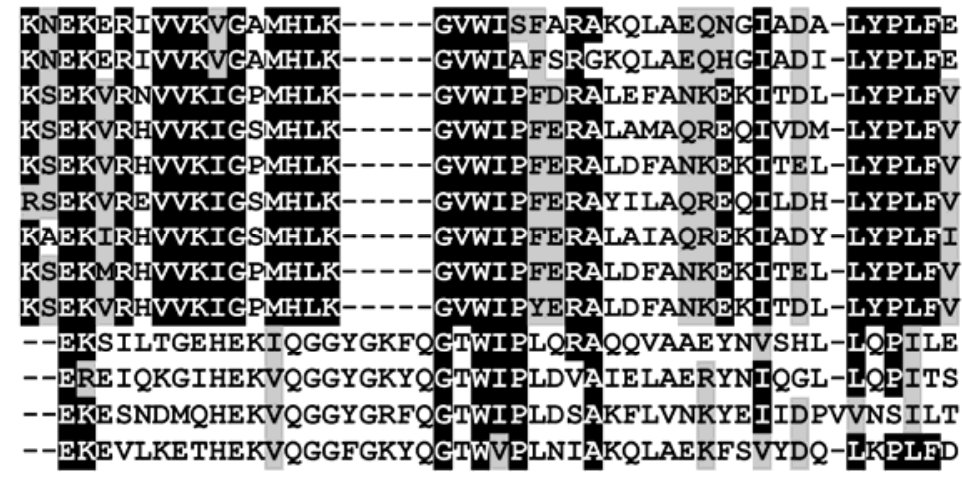

Fig. 2. Multiple alignment of the 97 amino acid APSES domain of Ustilago maydis Ust1 with similar domains from other fungal transcription factors. The APSES domains included are in the following order from the top: U. maydis, Ust1; Malassezia globosa; Aspergillus nidulans, StuA; Candida albicans, Efg1; Neurospora crassa, Asm1; Saccharomyces cerevisiae, Phd1; S. cerevisiae, Sok2; Magnaporthe grisea, Mstu1; and Penicillium marneffei, StuA. The APSES transcription factors from Malassezia globosa and Magnaporthe grisea have not been functionally characterized. Residues in black boxes are identical. Homologous residues are shaded in gray. The basic helix-loop-helix-like domains of two other U. maydis proteins (UM05338 and UM06196) are also shown to illustrate their much closer proximity to the cell cycle regulatory proteins Swi4 and Mpb1 than to the APSES transcription factors. U. maydis genes are underlined. 
in planta are diploid cells. Therefore, we additionally decided to delete ust 1 in a diploid solopathogenic background to test how repression of this activity in a condition that more closely resembles the ploidy of true teliospores would affect the expression of the mutant phenotype. A copy of $u s t l$ was first deleted in strain d132 (Table 1) using the mutant deletion construct containing the $c b x R$ marker, thus generating strain 14/28 (Table 1). Absence of one copy of ustl in strain 14/28 was confirmed by PCR analysis (data not shown). Then, a second mutant allele containing the hygR cassette as the selectable marker was transformed into strain 14/28 and, in this way, the double deletion strain 14/29 was obtained (Table 1). PCR analysis showed that the mutant allele containing the hygR cassette had integrated by homologous recombination in strain 14/29, and the absence of the ustl ORF in this strain (data not shown). Absence of the ust 1 transcript was further confirmed by Northern blot analysis (Fig. 3). Interestingly, this diploid double mutant exhibited an enhanced phenotype to that of haploid strains. Cultures of strain 14/29 became dark more rapidly and presented numerous aggregations of rounded cells with very dark thick walls (Fig. 5A). To determine their size compared with teliospores, the diameter of 25 darkly pigmented structures produced in 3-day-old cultures from strain 14/29 and 25 teliospores produced in plants inoculated with the diploid solopathogenic strain d132 were measured (Fig 5A and 5B). It was estimated that the average teliospore diameter was $9 \mu \mathrm{m}$ (ranging from 7.5 to $11.25 \mu \mathrm{m}$ ) and the average diameter of darkly pigmented structures produced in vitro was $11 \mu \mathrm{m}$ (ranging from 7.5 to $13.75 \mu \mathrm{m}$ ). One of the numerous aggregations of darkly pigmented structures found in liquid cultures of strain 14/29 is shown in Figure 5C. No other phenotypic differences with strains deleted for ust 1 in a haploid background were observed.

\section{Ust1 is required for mating, gall induction, and sporogenesis in maize tissue.}

To determine whether ustl played a role in cell fertility, charcoal plate mating (Holliday 1974) was performed. It should be noted here that, although ust 1 deletion mutants grow as filaments in liquid culture and their colony surfaces are dry, this filamentous growth is clearly distinguishable from the white aerial mycelium of the dikaryon produced upon mating. These differences made possible the use of plate mating assays to clearly establish a role for ust 1 in mating. Deletion mutant strains exhibited absent or severely reduced mating even when paired with wild-type strains (Fig. 6). Thus, in combinations between compatible wild-type strains $(1 / 2 \times 2 / 9)$, very strong aerial filamentous growth was observed $24 \mathrm{~h}$ after co-spotting (Fig. 6). However, matings where one strain was deleted for ust $1(1 / 2 \times 14 / 26$ or $2 / 9 \times 14 / 25)$ produced a gray colony surface (Fig. 6) with no white aerial mycelium visible, clearly indicating severely reduced mating and, thus, a critical role for ust 1 in this process. When two compatible mutant strains were paired, there was no visible production of dikaryotic hyphae. Consistent with this observation, preliminary microarray data indicate that basal expression of the pheromone encoding $\mathrm{mfal}$ gene is strongly downregulated in the $\Delta u s t 1$ strain compared with the wild type (F. Islamovic and S. Gold, unpublished).

The role of Ust1 during pathogenic development was investigated by inoculating maize seedlings with various pairwise combinations of compatible haploid wild-type and ust 1 deletion mutants. When combinations of wild-type and mutant strains $1 / 2 \times 14 / 26$ or $2 / 9 \times 14 / 25$ were used, a 75 and $60 \%$ reduction, respectively, in the number of plants with galls was observed compared with inoculation with two compatible wild-type strains (Table 2). Inoculation with two compatible mutant strains produced no galls. This result was not surprising because ust 1 , as discussed above, had been observed to be critical for mating. The presence of galls in a reduced number of plants when combinations of wild-type and compatible mutant strains were used indicates that, although plate mating assays produced no visible fuzzy growth, mating must occur in these combinations, albeit at reduced levels. To determine whether the reduction in virulence was due only to the effect on mating or, alternatively, that Ust1 also plays a post-mating role on pathogenicity, mutant strain 14/27, a ust 1-deleted solopathogenic haploid, was also used to inoculate plants. Solopathogenic strains bypass the requirement for a mating partner to cause disease. Plants inoculated with strain 14/27 showed symptoms indistinguishable from those induced by the solopathogenic strain SG200 at early stages of infection (4 to 5 days postinoculation). These symptoms were characterized by extensive chlorosis and areas of anthocyanin production. This result showed that the fungus was still able to penetrate and proliferate to some extent in plant tissue. However, at later stages of the disease, SG200 induced galls in the majority of plants whereas no galls were observed in plants inoculated with strain 14/27. In total, we inoculated 100 plants with the solopathogenic ust1 mutant (Table 2) without observing any gall production. Thus, plant inoculation studies indicated critical pre- and post-mating roles for ust 1 in pathogenicity. The ust 1 mutation clearly acted in a recessive manner in post-mating pathogenicity because mutants combined with the compatible wild-type strains were capable of producing typical galls in which teliospores were formed.

\section{Ust1 negatively regulates expression of the filament-downregulated gene UM00205 and the teliospore-specific gene ssp1.}

To study the role of Ust 1 on the regulation of gene expression, Northern blot analyses were performed. Three genes were chosen for this study: i) ssp 1, a gene identified as highly expressed in teliospores (Huber et al. 2002); ii) UM00205, identified as highly induced in budding cells (García-Pedrajas and Gold 2004) and which appears to be an ortholog of awh11, an A.

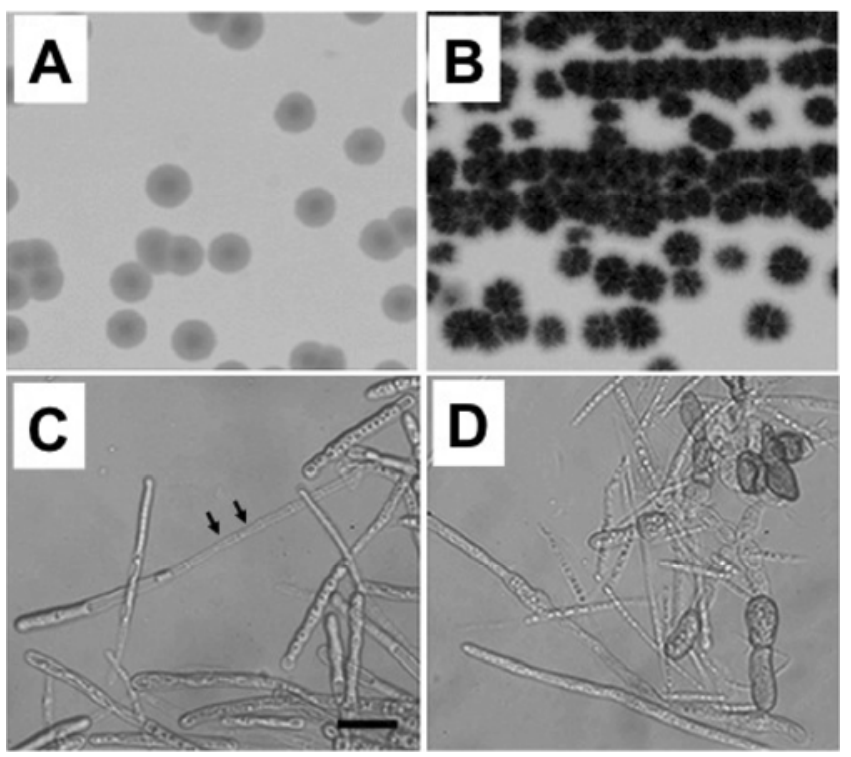

Fig. 4. Effect of ust1 deletion on colony and cell morphology. A and $\mathbf{B}$, Colonies of Ustilago maydis produced by the wild-type haploid strains $1 / 2$ and by 14/25, a ust 1 deletion mutant in the $1 / 2$ genetic background, respectively. Both strains were grown on potato dextrose agar supplemented to $2 \%$ agar. C and D, Cell morphology of ust 1 mutant strain 14/25 after 3 days of growth in potato dextrose broth; scale bar, $20 \mu \mathrm{m}$. C, Filamentous growth with areas devoid of cytoplasm (black arrows) and $\mathbf{D}$, highly pigmented spore-like structures are observed. 
nidulans gene directly under the regulation of StuA; and iii) UM03411, highly similar to endo- $\beta-1,4$-xylanases and also identified as upregulated in budding cells (García-Pedrajas and Gold 2004) but lacking StREs in its putative promoter region. This set of genes was chosen to start characterizing the effect of ust1 in dimorphism- and teliospore-related gene expression. Total RNA was extracted from several different haploid genetic backgrounds: haploid wild-type strain $1 / 2$, the constitutively filamentous uacl mutant strain $1 / 9$, a $u b c l$ mutant strain in which there is a constitutive activation of the cAMP pathway, the solopathogenic haploid strain SG200, and the ust1 mutant strain 14/25 (Table 1). All strains were grown for $24 \mathrm{~h}$ and the ustl mutant strain (14/25) was also grown for $72 \mathrm{~h}$ because the presence of dark spore-like structures became abundant by that time. Fragments containing a central portion of the predicted ORF of each gene were used as probes. Expression of sspl was very low in all conditions of in vitro growth tested, with the exception of the ust 1 mutant background, where expression was high after $72 \mathrm{~h}$ of growth (Fig. 7), coinciding with the abundant production of pigmented spore-like structures. As previously reported, UM00205 was induced in budding cells compared with $u a c l$ and $u b c l$ mutant backgrounds (García-Pedrajas and Gold 2004). This transcript was undetectable in a solopatho- genic background (Fig. 7). In the absence of $u s t$, expression of UM00205 was highly induced in agreement with a role for ust 1 as a repressor of this gene. Expression of the putative xylanase was not dramatically affected by $u s t 1$ deletion.

\section{DISCUSSION}

In this work, we describe the identification and functional characterization of a transcription factor containing a highly conserved bHLH-like APSES domain in the corn smut fungus $U$. maydis. The APSES proteins represent a conserved class of transcriptional regulators unique to fungi. StuA from $A$. nidulans, which regulates conidiophore development, was the first fungal regulatory protein reported in this class (Miller et al. 1992). Four other proteins with bHLH-like motifs highly similar to that of StuA were later identified: Asm-1 (N. crassa), Phd1 and Sok2 (S. cerevisiae), and Efg1 (C. albicans), and they were shown to regulate developmental processes in their respective species (Gimeno and Fink 1994; Ward et al. 1995; Aramayo et al. 1996; Stoldt et al. 1997). Therefore, it was proposed that the DNA-binding motif of these proteins, designated the APSES domain, defines a class of fungal transcription factors regulating development (Aramayo et al. 1996).
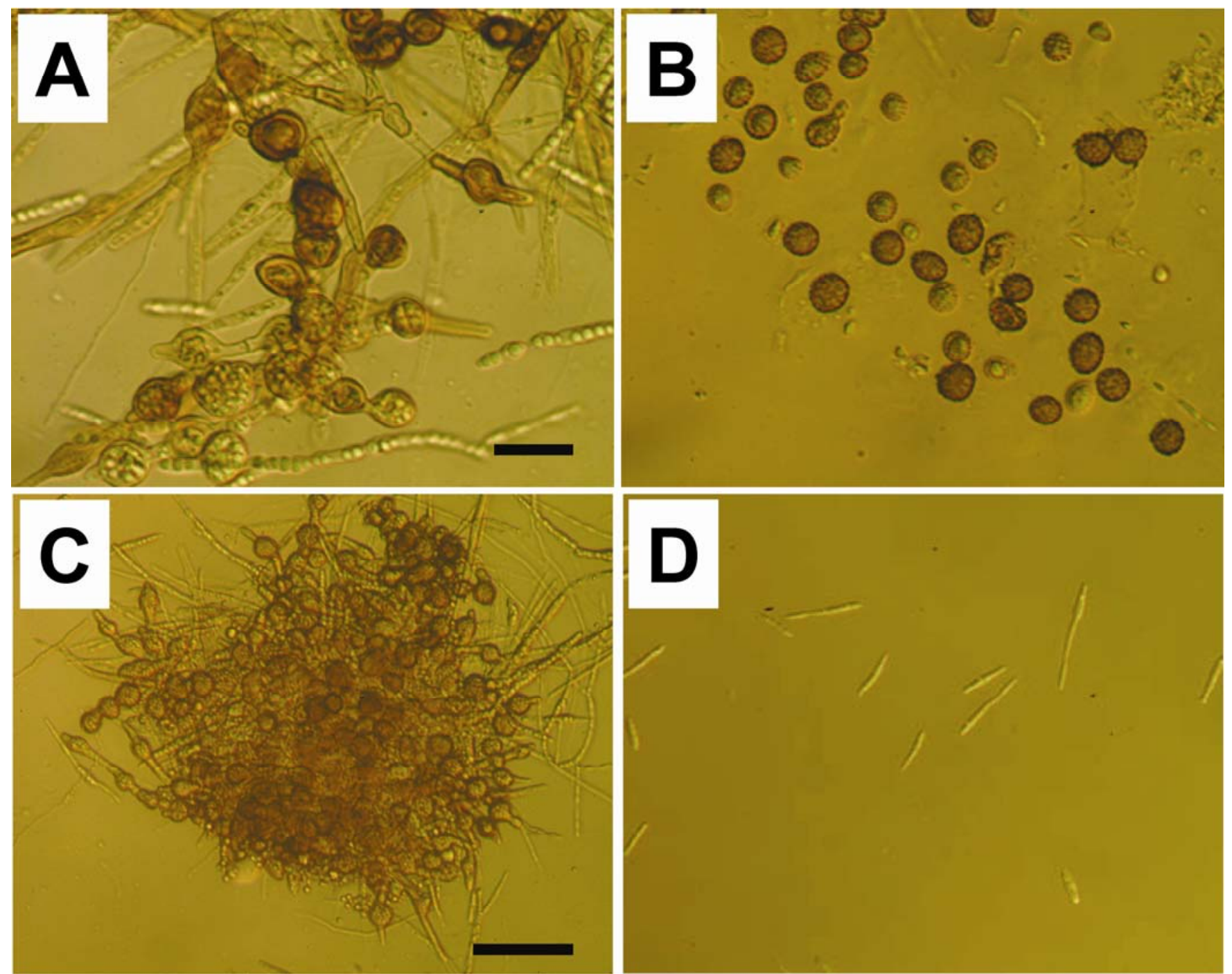

Fig. 5. In vitro spore-like structure production in diploid ust1 mutants. A, Comparison of the ust 1 null mutant strain in a diploid (d132) background 14/29, grown in potato dextrose broth for 3 days, with $\mathbf{B}$, teliospores of Ustilago maydis produced in planta by diploid solopathogenic strain d132. C, At a lower magnification, a cluster of darkly pigmented spore-like structures formed by this diploid mutant strains in liquid cultures. D, For comparison, the budding wild-type morphology of diploid strain d132. Scale bars: A and B, $20 \mu \mathrm{m} ; \mathrm{C}$ and D, $50 \mu \mathrm{m}$. 
The APSES domain shares limited but significant similarity with the bHLH motif of regulatory proteins involved in the cell cycle, typified by Mb1p and Swi4 (Fig. 2), which recognize a DNA sequence designated MCB (MluI cell cycle box) (Koch et al. 1993). Dutton and associates (1997) characterized the responsive element for A. nidulans StuA (StRE) and showed that it fits an MCB motif. Because of their highly conserved DNA-binding domain structure, APSES proteins from different species probably recognize similar sequences. Evidence to support this hypothesis was recently provided; Noffz and associates (2008) found that $C$. albicans Efg1 also binds an MCB motif and showed, by serial deletion analysis, that this binding is dependent on the APSES domain and adjacent sequences. The $C$. albicans genome contains a second APSES protein, Efh1. Noffz and associates (2008) also showed that a hybrid protein in which the APSES domain of Efg1 had been replaced by that of Efh1 was also able to bind to the MCB sequence.

APSES proteins play key roles in regulating dimorphic transitions in fungal species (Gimeno and Fink 1994; Ward et al. 1995; Stoldt et al. 1997), in some cases functioning as downstream effectors in cAMP signaling (Bockmühl and Ernst

\section{wt wt $\quad$ ust1 $\triangle u s t 1$ $a 1 b 1 a 2 b 2$ a1b1 a2b2}

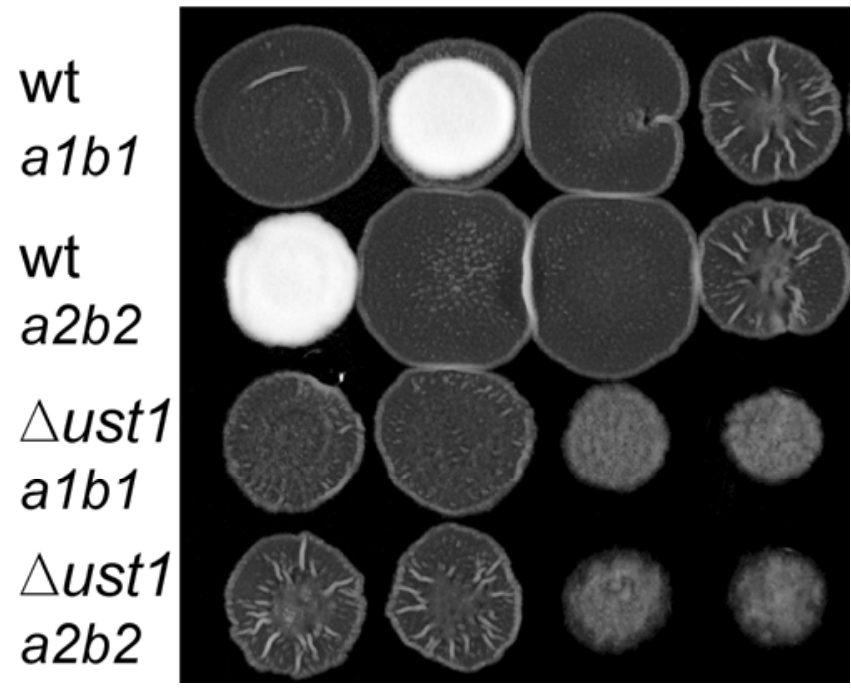

Fig. 6. Effect of ust 1 deletion on mating. Strains were grown in potato dextrose broth, wild-type strains overnight and ust 1 mutants for 2 days. Strains were then co-spotted on complete medium + charcoal and photographed after $25 \mathrm{~h}$ of incubation at room temperature.

Table 2. Pathogenicity of ust 1 deletion mutants

\begin{tabular}{|c|c|c|c|}
\hline Treatment $^{\mathrm{a}}$ & $\begin{array}{c}\text { ustl } \\
\text { genotype }\end{array}$ & $\begin{array}{l}\text { No. of plants } \\
\text { inoculated }\end{array}$ & $\begin{array}{l}\text { No. of plants } \\
\text { with galls }^{b}\end{array}$ \\
\hline 1 & $+/+$ & 20 & 16 \\
\hline 2 & $+/ \Delta u s t 1$ & 20 & 1 \\
\hline 3 & $\Delta u s t 1 /+$ & 20 & 4 \\
\hline 4 & $\Delta u s t 1 / \Delta u s t 1$ & 20 & 0 \\
\hline 5 & SG200 + & 100 & 91 \\
\hline 6 & SG200 $\Delta u s t 1$ & 100 & 0 \\
\hline
\end{tabular}

${ }^{a}$ In inoculations with solopathogenic strains, SG200 and $\Delta u s t 1$ in a SG200 background, two different cell concentrations were used. There was no statistical difference in the severity of symptoms caused by the two different cell concentrations and, therefore, the data was combined. Strains or strain combinations are as follows: treatment $1=(1 / 2 \times 2 / 9), 2=(1 / 2 \times$ $14 / 26), 3=(14 / 25 \times 2 / 9), 4=(14 / 25 \times 14 / 26), 5=$ SG200 (solopathogenic haploid), and $6=14 / 27$ ( $\Delta$ ust 1 SG200).

${ }^{\mathrm{b}}$ Recorded 14 days postinoculation.
2001), a pathway extensively studied in $U$. maydis (Barrett et al. 1993, Gold et al. 1994; Gold et al. 1997; Durrenberger et al. 1998; Krüger et al. 1998). Interestingly, we identified StREs in the putative promoter region of a number of genes differentially expressed in dimorphic growth in $U$. maydis (GarcíaPedrajas and Gold 2004), including that of a putative ortholog of an A. nidulans gene known to be directly regulated by StuA. These facts led us to hypothesize that an APSES protein may also play a role in regulating dimorphism in $U$. maydis. Search of the $U$. maydis genome database identified a single protein containing a motif closely resembling the APSES domain, which we named Ust1. Although the genomes of $S$. cerevisiae and Candida spp. contain two members of this class, possession of just a single APSES protein is more common in the fungi.

The role of Ust1 in $U$. maydis was investigated by generating deletion mutants. We were not able to complement the $\Delta$ ustl strains with a wild-type copy of ustl because numerous attempts to transform these mutants failed, even when using self-replicative plasmids that yield high transformation frequencies. However, we are confident that the phenotype observed is the result of $u s t l$ absence; 13 independent deletion mutants in several genetic backgrounds all exhibited the same phenotypic alterations, whereas these were never present in transformants where the deletion construct had integrated ectopically.

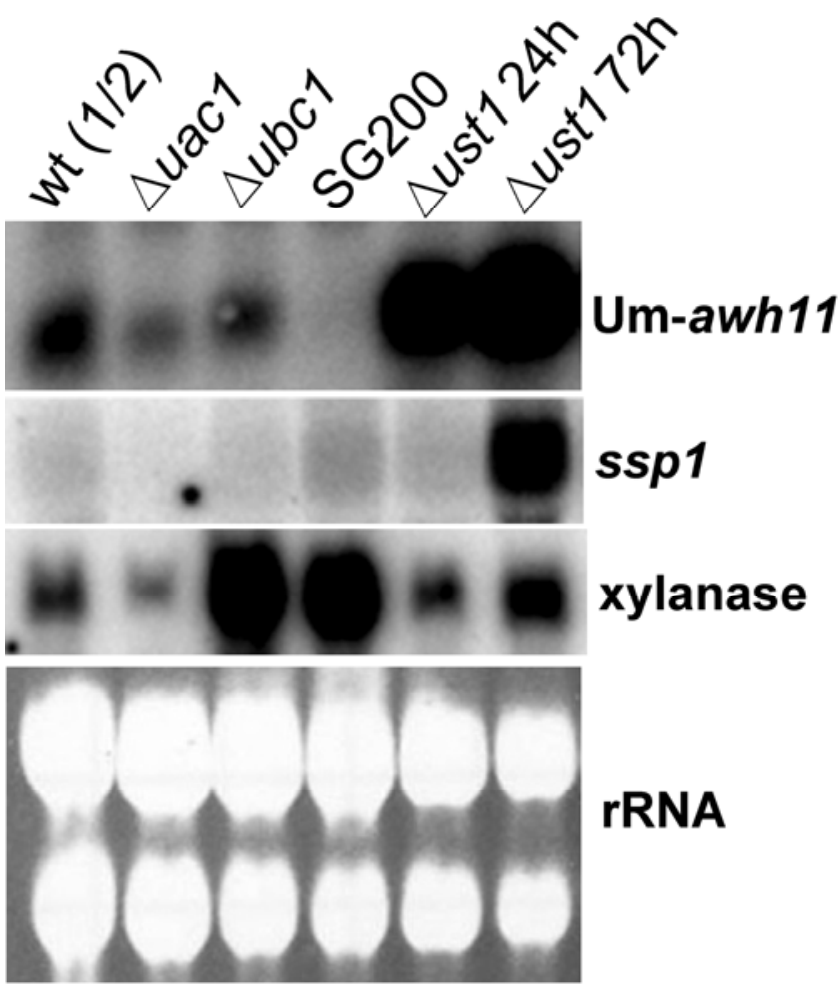

Fig. 7. Effect of ust 1 deletion on expression of selected genes. Ustilago maydis gene probes were derived from the filament-downregulated genes: awh11 putative ortholog, um-awh11 (UM00205), putative xylanase (UM03411) (García-Pedrajas and Gold 2004), and the spore-specific gene sspl (Huber et al. 2002). Strains listed were grown for $24 \mathrm{~h}$ in potato dextrose broth; the ust 1 null mutant was also grown for $72 \mathrm{~h}$. Total RNA was then extracted and hybridized with the different genes consecutively. In each case, the blot was probed, stripped, and then reprobed with the next probe. Probes were as follows: a fragment containing the entire open reading frame (ORF) of UM00205, an internal fragment of sspl (UM12271) ORF (from position 1,600 through 2,362), and an internal fragment of UM03411 ORF (from position 338 through 1,024). Strains tested were: $1 / 2$ (lane 1), 1/9 (lane 2), 1/68 (lane 3), SG200 (lane 4), 14/25 grown for $24 \mathrm{~h}$ (lane 5), and 14/25 grown for $72 \mathrm{~h}$ (lane 6). 
Ust1 regulates dimorphism in $\boldsymbol{U}$. maydis.

Absence of $u s t l$ in a haploid background converted cells from budding to filamentous growth, showing that it does, indeed, play a critical role in regulating dimorphism. To regulate transitions to or from budding modes of growth appears to be a conserved function of APSES proteins. In C. albicans, Efg1 regulates dimorphism, working as a downstream target of the cAMP pathway. Direct evidence of this link was obtained by analyzing how the phosphorylation status of a conserved putative PKA target in the APSES domain would affect Efg1 activity (Sonneborn et al. 1999; Bockmühl and Ernst 2001). In U. maydis, cAMP signaling is also a major regulator of dimorphism; disruption of this pathway in a haploid background leads to constitutive filamentous growth (Gold et al. 1994; Durrenberger et al. 1998). However, there are clear differences in the filamentous phenotypes induced by mutation of ust 1 and disruption of the cAMP pathway. Strains defective in cAMP signaling show profuse production of aerial mycelium on solid media; in $\Delta u s t l$ strains, on the other hand, although filamentous growth is readily observed in liquid media, on plates, production of aerial mycelium is not prominent. In S. cerevisiae, Pan and Heitman (2000) have also highlighted the clear morphological differences between the pseudohyphal growth induced by deletion of sok 2 and that attained by overexpression of cAMP signaling. These authors argue that these differences suggest that, even if APSES proteins are downstream targets of cAMP signaling in $S$. cerevisiae, as has been proposed (Ward et al. 1995), additional factors must come into play, further modulating their complex activity. Recently, Borneman and associates (2006) have provided evidence that Phd1 is a key node where several different pathways that regulate pseudohyphal growth converge. Even in $C$. albicans, where cAMP signaling is known to positively regulate Efg1 activity, this activity appears to be controlled in a complex manner. Thus, Bastidas and associates (2009) have proposed that regulation of cellular adhesion by the Tor pathway involved Efg1. According to this model, the Tor kinase Tor1 would negatively regulate Efg1 activity (Bastidas et al. 2009).

Because ust 1 was identified as a putative regulator of filament-downregulated genes and because ustl mutants are unable to bud, to start characterizing the putative role of Ust1 in regulating bud-filament differential gene expression, we determined the effect of ust 1 on the expression of UM00205, a putative ortholog of the StuA-regulated gene $a w h 11$, which we had earlier shown to be differentially transcribed in budding versus filamentous growth (García-Pedrajas and Gold 2004). We found that deletion of ust 1 in a budding haploid background, in which UM00205 is normally expressed, greatly increased its level of expression. This result suggests a role as a transcriptional repressor for Ust1. Thus, Ust1 may play a significant role in maintaining appropriate levels of expression of genes normally expressed in, and perhaps determinant of, the budding phase. The conserved APSES domain does not confer regulatory specificity; thus, there is evidence of these proteins working as both repressors and activators of transcription (Gimeno and Fink 1994; Ward et al. 1995; Lo et al. 1997; Stoldt et al. 1997; Shenhar and Kassir 2001; Doebt et al. 2004). Although our data suggest that Ust1 likely functions as a repressor for some genes, a role as an activator of an additional set of genes cannot be disregarded. Efg1 and StuA are known to activate the expression of some genes while repressing others (Dutton et al. 1997; Stoldt et al. 1997; Shenhar and Kassir 2001; Scherer et al. 2002; Doebt et al. 2004).

\section{Lack of Ust1 promotes formation of thick-walled pigmented spore-like cells in axenic culture.}

We observed that, in cultures of $\Delta u s t 1$ mutants, large numbers of irregularly shaped to spherical cells with highly pig- mented thick walls resembling spores were formed. In $U$. maydis, the sexual cycle can be completed only in the host plant and results in the formation of diploid spores with thick, melanized walls termed teliospores. The morphological changes that take place in hyphae leading to the formation of teliospores have been studied in detail (Banuett and Herskowitz 1996). Profuse branching of hyphae proliferating within plant tumors signals the beginning of teliospore formation; tips of many hyphae then take on a bulbous appearance, hyphal fragmentation takes place, and cells round; finally, a pigmented sculpted (echinulate) cell wall is deposited (Banuett and Herskowitz 1996). There is strong evidence that cAMP signaling negatively regulates teliospore formation in the host (Krüger et al. 2000). Interestingly, though, strains with no or reduced levels of cAMP do not induce any structures resembling spores in culture, indicating that repression of cAMP signaling alone is not sufficient to induce the spore development program. By contrast, ust 1 null mutants grown in axenic culture produce large numbers of thick-walled, highly pigmented, rounded cells that resemble masses of developing teliospores observed in immature galls. We also observed a high degree of cell lysis in these mutants. Interestingly, cDNA arrays demonstrated a role for Efg 1 in cell wall biogenesis in C. albicans (Sohn et al. 2003). This phenotype suggests that Ust1 might be downregulated during teliosporogenesis and that, unlike cAMP signaling, its repression alone is sufficient to derepress a battery of genes leading to production of rounded structures, hyphal fragmentation, and deposition of thick, melanized cell walls, although these are not echinulate like in mature teliospores. We attempted to further characterize the potential role of Ust1 in repressing teliospore formation by deleting ust 1 in a diploid background that more closely resembles the ploidy condition in which teliospore are produced. This work was, in part, aimed to determine whether the pigmented cells observed in the mutants had the ability to germinate and undergo meiosis. However, the only phenotypic difference observed between the ust 1 mutants in the diploid or haploid backgrounds was that the production of spore-like structures was enhanced in the former. However, this is not surprising because, as ust 1 is required for budding growth, induction of its expression might be required for teliospore germination and production of sporidia. Thus, other methods need to be explored to test germination potential of $\Delta u s t 1$ spore-like structures, such as the use of conditional promoters.

In $U$. maydis, in addition to $a d r l$, which encodes the catalytic subunit of PKA (Durrenberger et al. 1998), other genes encoding protein kinases related in structure to PKA and playing roles in morphogenesis have been identified. One of them is $u k c 1$, which codes for a serine/threonine kinase related in structure to cAMP-dependent PKA but clearly distinct from them (Durrenberger and Kronstad 1999). Interestingly, mutants in $u k c l$ somewhat resembled those deleted for ustl. Strains mutated in either $u k c l$ or $u s t l$ produced highly pigmented cells in vitro; both mutants were also deficient in the formation of mating-induced aerial mycelium even when paired with compatible wild-type strains, and they could infect corn plants and cause symptoms but they were unable to induce galls. These results suggest that Ust1 might be a substrate for Ukc1 phosphorylation. However, there are also differences in the phenotype induced by these mutations (e.g., the clear filamentous growth exhibited by ust 1 mutants in liquid media is not observed in $u k c 1$ mutants). These differences suggest that, even if Ust1 is indeed a target of Ukc1, other regulatory mechanisms must also affect Ust1 activity. Beyond the scope of the current study, epistasis experiments are required to establish the putative link between Ukc1 and Ust1.

Ust1 appears to follow the general pattern of roles previously described for APSES proteins in ascomycetes. These transcrip- 
tion factors regulate sexual or asexual sporulation in a wide range of species (Clutterbuck 1969; Miller et al. 1991; Aramayo et al. 1996; Wu and Miller 1997; Sonneborn et al. 1999; Pan and Heitman 2000; Borneman et al. 2002; Ohara and Tsuge 2004; Sheppard et al. 2005; Tong et al. 2007). Asexual spores produced by haploid strains under certain stress conditions, and characterized as chlamydospores, have also been reported in U. maydis (Kusch and Schauz 1989). However, their roles in the life cycle of this fungus remain unknown. Ust1 might regulate the production of sexual or asexual spores; a number of features, such as a transition in mode of growth and deposition of melanized thick walls, are common to both processes. However, it should be noted that, in contrast to the stress-induced pigmented cells, ust 1 mutant cells do not produce lateral hyphal projections (Figs. 4D and 5A and C). Additionally, whereas, in stress-related chlamydospores, cells in chains are closely clustered together, in ust 1 mutants, individual pigmented cells are often separated by filamentous areas of variable length.

As well as the first for the Basidiomycota, Ust1 is the first APSES protein characterized in a semiobligate parasite, fully dependent on the host for sexual sporulation processes. To determine whether there is a connection between the rounded cells with thick, pigmented walls observed in cultures of ust 1 mutants and teliospores produced in planta is of considerable interest. To have a mutant that mimics teliospore production in vitro could help elucidate the molecular mechanisms and triggering signals of this developmental process. To start investigating the putative role of Ust 1 in repressing the teliospore development program, we analyzed the expression of sspl, a gene identified as highly expressed in teliospores and very lowly expressed in axenic cultures (Huber et al. 2002). Comparing wild-type and $\Delta u s t 1$ deletion mutants, we found that sspl expression is highly derepressed in the latter. The gene sspl does not appear to be under direct regulation of ustl because it is not expressed in early (at $24 \mathrm{~h}$ ) ust 1 mutant cultures where the pigmented spore-like structures have not yet begun to develop but, rather, becomes abundantly expressed later (at $72 \mathrm{~h}$ ), when the pigmented cells are also abundant. Expression of sspl appears, instead, to be under the regulation of a factor that is, in turn, directly or indirectly regulated by Ust1. This result indicates that there is at least some overlap between expression patterns of teliospores and these dark structures produced in culture in the ustl mutant, which suggests that ust 1 may function as a repressor of genes normally induced during teliospore formation.

\section{Ust1 is required for mating and gall induction.}

We also investigated how loss of $u s t l$ would influence mating and pathogenicity, revealing a critical role for Ust 1 in both processes. The ust 1 null mutants were deficient in the formation of aerial mycelium even when paired with compatible wild-type strains. In agreement with the observed role in mating for Ust1, we found a decrease in disease severity in inoculations with compatible pairs of wild-type and mutant strains. However, some of the plants produced galls, showing that, although we did not detect formation of aerial mycelium in compatible combinations of wild-type and mutant strains, mating takes place at a low level. These galls had normal morphology and produced melanized teliospores, indicating that a single copy of ust 1 is sufficient to complete the disease cycle and, therefore, that ustl plays a recessive role in these processes. No galls were obtained in plants inoculated with two compatible ust 1 haploid mutants. To investigate whether this was due solely to defective mating or whether Ust1 also played a postmating role in pathogenicity, we deleted ust 1 in a solopathogenic haploid background. Interestingly, we found that Ust1 was not required for penetration or the initial steps of infection but it was critical for gall induction.
APSES transcription factors have not been widely studied in fungal pathogens and, therefore, their role in pathogenicity is not well characterized. Deletion of Fusarium oxysporum FoSTUA had a major effect on sporulation processes but did not result in decreased virulence (Ohara and Tsuge 2004). Recently, an APSES protein was characterized in an appressoriumforming pathogen, Glomerella cingulata. Interestingly, mutants lacking this activity formed appressoria with normal morphology but significantly reduced turgor pressure, which led to their inability to penetrate epidermal cells (Tong et al. 2007). In recent years, a role for APSES transcription factors as key regulators of the expression of metabolic enzymes has also emerged (Doedt et al. 2004; Sheppard et al. 2005). Tong and associates (2007) argued that mutants lacking GcSTUA were affected in metabolic pathways critical for generating appressorial turgor pressure. In the present work, we have established that ust 1 plays important roles affecting the development of disease caused by $U$. maydis in both a pre- and post-mating manner. Further investigation is required to determine whether this is due solely to the role of Ust1 in regulating morphological transitions critical to complete the disease cycle or also to its putative control of metabolism during in planta growth or other activities required for biotrophic growth.

\section{Conclusions and future work.}

We have shown that Ust1 activity is required to maintain wild-type budding morphology. Ust1 is also critical for mating, for fungal proliferation and gall induction in planta, as well as for repressing spore formation in vitro. Our finding that sspl, a gene highly expressed in teliospores, is highly derepressed in ust 1 mutant cultures suggests a potential role for Ust1 in repressing teliospore formation during pathogenic development. This is in agreement with the functions described for APSES domain proteins in other fungi; they are critical factors regulating multiple differentiation processes within a single species.

Future work to clarify the role of Ust1 in morphogenesis, pathogenicity, and sporogenesis in $U$. maydis will focus on three major aspects: i) to investigate how Ust1 coordinates its function with other factors and pathways known to control these processes, ii) to identify its target genes to determine which cellular activities are specifically regulated by this transcription factor, and iii) to analyze the roles of transcriptional and post-translational regulation of $u s t 1$.

\section{MATERIALS AND METHODS}

Fungal and bacterial strains and growth conditions.

U. maydis strains in this study (Table 1) were maintained on PDA (Difco, Franklin Lakes, NJ, U.S.A.) supplemented to $2 \%$ agar (2PDA) and grown at $30^{\circ} \mathrm{C}$. Transformants were grown on double complete medium with $1 \mathrm{M}$ sorbitol (Holliday 1961 ) and carboxin at $3 \mu \mathrm{g} / \mathrm{ml}$ (Keon et al. 1991) or hygromycin B at $300 \mu \mathrm{g} / \mathrm{ml}$ (Barrett et al. 1993), according to the selectable marker used in the transformation. Transformants were propagated on 2PDA supplemented with either carboxin $(3 \mu \mathrm{g} / \mathrm{ml})$ or hygromycin B $(150 \mu \mathrm{g} / \mathrm{ml})$. Potato dextrose broth (PDB, Difco) was used for most fungal liquid cultures except for growing cells to produce protoplasts, in which case YEPS (1\% yeast extract, $2 \%$ bacto peptone, $2 \%$ sucrose) was used. All liquid cultures were grown at $250 \mathrm{rpm}$ at $30^{\circ} \mathrm{C}$. Escherichia coli strain DH5 $\alpha$ (Bethesda Research Laboratories, Gaithersburg, MD, U.S.A.) was used for DNA manipulations except for cloning in pCR 2.1-TOPO vector (Invitrogen, Carlsbad, CA, U.S.A.), in which case E. coli strain TOP10 was used. E. coli was grown in or on Luria-Bertani (LB) medium amended with appropriate antibiotics. 


\section{RNA manipulations.}

For total RNA purification from $U$. maydis for RNA blot hybridization and as a source for PolyA ${ }^{+}$RNA, strains were grown as described above; cells were then harvested by centrifugation and immediately frozen in liquid nitrogen. RNA was purified using TRIzol Reagent (Invitrogen) as previously described (García-Pedrajas and Gold 2004). RNA samples were resuspended in nuclease-free water and quantified by measuring absorbance at $260 \mathrm{~nm}$. Total RNA (15 $\mu \mathrm{g} / \mathrm{sample})$ was used for Northern blot hybridizations that were performed as previously described (García-Pedrajas and Gold 2004). PolyA ${ }^{+}$RNA, to be used as a template for RACE, was purified from total RNA using the NucleoTrap mRNA purification kit (BD Biosciences, Palo Alto, CA, U.S.A.).

\section{RACE.}

To characterize the full-length ust 1 cDNA using the SMART RACE cDNA amplification kit (BD Biosciences), primers GSP1-ust1 (GCTCAAAGAGAGGATAGAGCGCATC GGC) and GSP2-ust1 (ACGACACCGTGTCACCACCACGC TGTGG) were designed to amplify the $5^{\prime}$ and $3^{\prime}$ ends, respectively. cDNA synthesis and amplifications were performed according to the manufacturer's instructions. The starting material was $1 \mu \mathrm{g}$ of PolyA ${ }^{+}$RNA prepared from strain 1/2 (Table 1) grown for $18 \mathrm{~h}$ in PDB. Amplified bands were cloned into pCR2.1-TOPO vector (Invitrogen) and sequenced using M13 forward and reverse primers. Sequencing was carried out in part by the Molecular Genetics Instrumentation Facility at the University of Georgia and also in our laboratory using the Big Dye Terminator Cycle sequencing kit (Applied Biosystems, Foster City, CA, U.S.A.) and run on an ABI Prism 310 Capillary Automated Genetic Analyzer (Applied Biosystems) at the Genome Analysis Facility on site. DNA sequences were analyzed with MacDNAsis v3.5 software. (Hitachi Software Engineering Co. Ltd., San Francisco).

\section{Deletion of ust1.}

Cloning procedures were carried out with standard techniques (Ausubel et al. 1987; Sambrook et al. 1989). PCR products were cloned into the TA vector pCR2.1-TOPO (Invitrogen) according to manufacturer's instructions. U. maydis transformations were performed according to Tsukuda and associates (1988).

To create a ust 1 deletion construct with a $c b x R$ selectable marker, the method described by Davidson and associates (2002) and based on overlap PCR was used. For this, $1 \mathrm{~kb}$ of the $5^{\prime}$ and $3^{\prime}$ sequences flanking the ust 1 ORF were amplified, as well as the $c b x R$ marker. The $5^{\prime}$ flank was amplified using primers ust1-1 (TCTTCACCCTGCATTTCGC) and ust1-3 (CAGCGAACGGCGTTCTTCAACTATAACGCGTCACGC TG). The 3' flank was amplified using primers ust1-4 (GCG AGACGAGTTGAGCGAAGTCTTGCTTTCTGCGCACG) and ust1-6 (CATGTCGTTGCAGGGATCC). The selectable $c b x R$ marker was amplified with primers ust1-2 (CAGCGTG ACGCGTTATAGTTGAAGAAGCCGTTCGCTG) and ust1-5 (CGTGCGCAGAAAGCGAGACTTCGCTCAACTCGTCT $\underline{\mathrm{CGC}})$. The text in bold corresponds to the ustl-specific sequences while the underlined text corresponds to the part of the primers homologous to the $c b x R$-selectable marker. Primer ust $1-3$ is complementary to primer ust $1-2$ and primer ust $1-5$ is complementary to primer ust1-4. These three fragments were separately amplified in a first round of PCR using a PerkinElmer Applied Biosystems 9600 thermocycler. The reactions consisted of a initial denaturation of $2 \mathrm{~min}$ at $95^{\circ} \mathrm{C}$; followed by 35 cycles of $30 \mathrm{~s}$ at $95^{\circ} \mathrm{C}, 30 \mathrm{~s}$ at $56^{\circ} \mathrm{C}$, and $2 \mathrm{~min}$ at $72^{\circ} \mathrm{C}$; and was completed with a final extension of $5 \mathrm{~min}$ at $72^{\circ} \mathrm{C}$. Bands were then purified using a Qiaquik column (Qiagen, Valencia, CA, U.S.A.) and pooled together, and $1 \mu$ was used for the overlap PCR using primer ust1-1nested (GGTCTTTG AGCTGCTCTTGTTGAGC) and ust1-6nested (ATCTTTTG GATGGCTCCCGAAGTGG). For this second PCR, an initial denaturation was performed for $2 \mathrm{~min}$ at $95^{\circ} \mathrm{C}$; followed by 35 cycles of $15 \mathrm{~s}$ at $95^{\circ} \mathrm{C}, 15 \mathrm{~s}$ at $62^{\circ} \mathrm{C}$, and $5 \mathrm{~min}$ at $72^{\circ} \mathrm{C}$; and completed with a final extension of $5 \mathrm{~min}$ at $72^{\circ} \mathrm{C}$. After amplification, the PCR product was run on a $0.8 \%$ agarose gel, and the band of $4.25 \mathrm{~kb}$ was excised from the gel, purified using a Qiaquik column (Qiagen), and cloned into pCR2.1-TOPO vector to produce the ustl deletion construct plasmid pust1KOCbx. The linear deletion construct for $U$. maydis transformation was generated by amplifying it from pust1KO-Cbx with primers ust1-1nested and ust1-6nested. The PCR product was precipitated with ethanol and resuspended in distilled water prior to transformation.

To produce a $u s t 1$ deletion construct with the $h y g R$ cassette as the selectable marker, first, the $c b x R$ mutant allele was transferred from pCR2.1-TOPO to pBS KSII+ (Stratagene, La Jolla, CA, U.S.A.), thus generating plasmid pBSust1KO-cbx. Then, approximately $1 \mathrm{~kb}$ of the $c b x R$ marker in this plasmid was replaced with the $h y g R$ cassette by digesting with $B g l \mathrm{II}$ and inserting the hygR band excised from pIC19RHL (Mayorga and Gold 2001) with BamHI $+B g l I I$, thus generating plasmid pust1KO-Hyg. This $h y g R$ construct was used to produce a diploid strain mutated for both alleles of ust 1 . This strain was generated by first deleting one allele with the $c b x R$ construct and then the second with the hygR cassette. In the transformation with the $h y g R$ construct, to avoid transformants in which this had integrated replacing the $c b x R$ mutated allele, only those that were resistant to both carboxin and hygromycin were selected; integration of the hygR construct in the $c b x R$ allele would render strains sensitive to carboxin.

To analyze $U$. maydis transformants for gene replacement, the primer combination ust1-F (TCGGCTTCGGGTTCCA TGTACG) and ust1-R (ATCGAGCTTGAGGCCGTTCGAG), which amplify an internal fragment of the ustl ORF, was first used. Those transformants that did not produce a band with ust $1-\mathrm{F}$ and ust1-R were then amplified with primers ust $1-1$ and ust 1-5, which generate a band only in transformants in which gene replacement had taken place. Amplifications were performed in the same conditions previously described for the overlap PCR.

\section{Mating and pathogenicity assays.}

For plate mating reactions, strains were co-spotted onto $1 \%$ charcoal plates as previously described by Holliday (1974). Wild-type strains were grown overnight in PDB whereas ust 1 mutants were grown for 2 days because they grew slowly and exhibited very little growth after overnight incubation. From each PDB culture, $5 \mu \mathrm{l}$ was then spotted on charcoal plates and, when dried, overlaid with $5 \mu$ of the respective mating partner. After the spots were completely dried, plates were wrapped with Parafilm and incubated for $24 \mathrm{~h}$ at room temperature.

Golden Bantam (Athens Seed Co., Watkinsville, GA, U.S.A.) seedlings were grown in sterilized potting soil and, at 10 days, inoculated according to procedures previously described (Gold et al. 1997; Mayorga and Gold 1999). For plant inoculation, wild-type strains were grown overnight in PDB whereas mutant strains were grown for 2 days due to their slow growth. Wild-type haploid strains were grown overnight and then diluted in inoculation mixtures at an approximate concentration of $10^{6}$ cells $\mathrm{ml}^{-1}$. In cultures of $u s t 1$ mutants, it was not possible to count cells due to their filamentous morphology; to make sure that enough cells of these strains were added, cultures were grown for 2 days because these are slow-growth strains, and then diluted 25 times for the inoculation mixtures. 
When using the mutant strain in a solopathogenic background, a further attempt was made to make sure that a sufficient inoculum was used in the pathogenicity assays by using two different dilutions of the cultures. Cells were grown for 2 days and then these cultures where diluted 10 and 50 times and each dilution used to inoculate 25 plants Overnight cultures of SG200 were also diluted to two concentration, $10^{6}$ and $5 \times 10^{6}$ cells $\mathrm{ml}^{-1}$, and each cell dilution was used to inoculate 25 plants. In this way, we could determine how the inoculum density affected disease severity. The inoculation experiment with solopathogenic strains was repeated twice; therefore, in total, 100 plants were inoculated with each strain. The progression of the disease was observed 7, 10, and 14 days after inoculation. Because the disease severity for a given strain was very similar regardless of the inoculum density used, the data obtained with the two cell concentrations was combined.

\section{ACKNOWLEDGMENTS}

We thank D. L. Andrews for assistance with sequencing. This work was supported by UDSA-NRI grants 20013531910139 and 20033531913361.

\section{LITERATURED CITED}

Adams, T. H., Wieser, J. K., and Yu, J. H. 1998. Asexual sporulation in Aspergillus nidulans. Microbiol. Mol. Biol. Rev. 62:35-54.

Andrews, D. L., Egan, J. D., Mayorga, M. E., and Gold, S. E. 2000. The Ustilago maydis $u b c 4$ and $u b c 5$ genes encode members of a MAP kinase cascade required for filamentous growth. Mol. Plant-Microbe Interact. 13:781-786.

Aramayo, R., Peleg, Y., Addison, R., and Metzenberg, R. 1996. Asm-1+, a Neurospora crassa gene related to transcriptional regulators of fungal development. Genetics 144:991-1003.

Ausubel, F. M., Brent, R., Kingston, R. E., Moore, D. D., Seidman, J. G., Smith, J. A., and Struhl, K. 1987. Current Protocols in Molecular Biology. Greene Publishing Associates/Wiley-Interscience, New York.

Banuett, F., and Herskowitz, I. 1996. Discrete developmental stages during teliospore formation in the corn smut fungus, Ustilago maydis. Development 122:2965-2976.

Barrett, K. J., Gold, S. E., and Kronstad, J. W. 1993. Identification and complementation of a mutation to constitutive filamentous growth in Ustilago maydis. Mol. Plant-Microbe Interact. 6:274-283.

Bastidas, R. J., Heitman, J., and Cardenas, M. E. 2009. The protein kinase Tor1 regulates adhesin gene expression in Candida albicans. PLoS Pathog. 5:e1000294.

Bockmühl, D. P., and Ernst, J. F. 2001. A potential phosphorylation site for an A-type kinase in the Efg1 regulator protein contributes to hyphal morphogenesis of Candida albicans. Genetics 157:1523-1530.

Bölker, M., Urban, M., and Kahmann, R. 1992. The $a$ mating type locus of Ustilago maydis specifies cell signaling components. Cell 68:441-450.

Borneman, A. R., Hynes, M. J., and Andrianopoulos, A. 2002. A basic helix-loop-helix protein with similarity to the fungal morphological regulators, Phd1p, Efg1p and StuA, controls conidiation but not dimorphic growth in Penicillium marneffei. Mol. Microbiol. 44:621-631.

Borneman, A. R., Leigh-Bell, J. A., Yu, H., Bertone, P., Gerstein, M., and Snyder, M. 2006. Target hub proteins serve as master regulators of development in yeast. Genes Dev. 20:435-448.

Braun, B. R., and Johnson, A. D. 2000. TUP1, CPH1 and EFG1 make independent contributions to filamentation in Candida albicans. Genetics 155:57-67.

Brefort, T., Müller, P., and Kahmann, R. 2005. The high-mobility-group domain transcription factor Rop1 is a direct regulator of prf1 in Ustilago maydis. Eukaryot. Cell 4:379-391.

Brefort, T., Doehlemann, G., Mendoza-Mendoza, A., Reissmann, S., Djamei, A., and Kahmann, R. 2009. Ustilago maydis as a pathogen. Annu. Rev. Phytopathol. 47:423-445.

Callow, J .A., and Ling, I. T. 1973. Histology of neoplasms and chlorotic lesions in maize seedlings following injection of sporidia of Ustilago maydis (Dc) Corda. Physiol. Plant Pathol. 3: 489.

Chew, E., Aweiss, Y., Lu, C. Y., and Banuett, F. 2008. Fuz1, a MYND domain protein, is required for cell morphogenesis in Ustilago maydis. Mycologia 100:31-46.

Christensen, J. J. 1963. Corn Smut Caused by Ustilago maydis, Monograph No. 2. American Phytopathological Society Press, St. Paul, MN, U.S.A.
Clutterbuck, A. J. 1969. A mutational analysis of conidial development in Aspergillus nidulans. Genetics 63:317-327.

Davidson, R. C., Blankenship, J. R., Kraus, P. R., de Jesus Berrios, M., Hull, C. M., D’Souza, C., Wang, P., and Heitman, J. 2002. A PCR-based strategy to generate integrative targeting alleles with large regions of homology. Microbiology 148:2607-2615.

Doedt, T., Krishnamurthy, S., Bockmuhl, D. P., Tebarth, B., Stempel, C., Russell, C. L., Brown, A. J., and Ernst, J. F. 2004. APSES proteins regulate morphogenesis and metabolism in Candida albicans. Mol. Biol. Cell 15:3167-3180.

Durrenberger, F., and Kronstad, J. 1999. The $u k c 1$ gene encodes a protein kinase involved in morphogenesis, pathogenicity and pigment formation in Ustilago maydis. Mol. Gen. Genet. 261:281-289.

Durrenberger, F., Wong, K., and Kronstad, J. W. 1998. Identification of a cAMP-dependent protein kinase catalytic subunit required for virulence and morphogenesis in Ustilago maydis. Proc. Natl. Acad. Sci. U.S.A. 95:5684-5689.

Durrenberger, F., Laidlaw, R. D., and Kronstad, J. W. 2001. The hgll gene is required for dimorphism and teliospore formation in the fungal pathogen Ustilago maydis. Mol. Microbiol. 41:337-348.

Dutton, J. R., Johns, S., and Miller, B. L. 1997. StuAp is a sequence-specific transcription factor that regulates developmental complexity in Aspergillus nidulans. EMBO (Eur. Mol. Biol. Organ.) J. 16:5710-5721.

García-Pedrajas, M. D., and Gold, S. E. 2004. Fungal dimorphism regulated gene expression in Ustilago maydis: II. Filament downregulated genes. Mol. Plant Pathol. 5:295-308.

Gillissen, B., Bergemann, J., Sandmann, C., Schroeer, B., Bölker, M., and Kahmann, R. 1992. A two-component regulatory system for self/nonself recognition in Ustilago maydis. Cell 68:647-657.

Gimeno, C. J., and Fink, G. R. 1994. Induction of pseudohyphal growth by overexpression of PHD1, a Saccharomyces cerevisiae gene related to transcriptional regulators of fungal development. Mol. Cell Biol. $14: 2100-2112$

Gold, S., Duncan, G., Barrett, K., and Kronstad, J. W. 1994. cAMP regulates morphogenesis in the fungal pathogen Ustilago maydis. Genes Dev. 8:2805-2816.

Gold, S. E., Brogdon, S. M., Mayorga, M. E., and Kronstad, J. W. 1997. The Ustilago maydis regulatory subunit of a cAMP-dependent protein kinase is required for gall formation in maize. Plant Cell 9:1585-1594.

Hartmann, H. A., Kahmann, R., and Bölker, M. 1996. The pheromone response factor coordinates filamentous growth and pathogenicity in Ustilago maydis. EMBO (Eur. Mol. Biol. Organ.) J. 15:1632-1641.

Holliday, R. 1961. Induced mitotic crossing-over in Ustilago maydis. Genet. Res. 2:231-248.

Holliday, R. 1974. Ustilago maydis. Pages 575-595 in: Handbook of Genetics. R. C. King, ed. Plenum, New York.

Huber, S. M., Lottspeich, F., and Kamper, J. 2002. A gene that encodes a product with similarity to dioxygenases is highly expressed in teliospores of Ustilago maydis. Mol. Genet. Genomics 267:757-771.

Kaffarnik, F., Muller, P., Leibundgut, M., Kahmann, R., and Feldbrugge, M. 2003. PKA and MAPK phosphorylation of Prf1 allows promoter discrimination in Ustilago maydis. EMBO (Eur. Mol. Biol. Organ.) J. 22: $5817-5826$

Kahmann, R., Basse, C., and Feldbrugge, M. 1999. Fungal-plant signalling in the Ustilago maydis-maize pathosystem. Curr. Opin. Microbiol. 2:647-650.

Kamper, J., Reichmann, M., Romeis, T., Bölker, M., and Kahmann, R. 1995. Multiallelic recognition: nonself-dependent dimerization of the $\mathrm{bE}$ and bW homeodomain proteins in Ustilago maydis. Cell 81:73-83.

Keon, J. P., White, G. A., and Hargreaves, J. A. 1991. Isolation, characterization and sequence of a gene conferring resistance to the systemic fungicide carboxin from the maize smut pathogen, Ustilago maydis. Curr. Genet. 19:475-481.

Koch, C., Moll, T., Neuberg, M., Ahorn, H., and Nasmyth, K. 1993. A role for the transcription factor Mbp1 and Swi4 in progression from G1 to S-phase. Science 261:1551-1557.

Kronstad, J. W., and Leong, S. A. 1989. Isolation of two alleles of the $b$ locus of Ustilago maydis. Proc. Natl. Acad. Sci. U.S.A. 86:978-982.

Krüger, J., Loubradou, G., Regenfelder, E., Hartmann, A., and Kahmann, R. 1998. Crosstalk between cAMP and pheromone signalling pathways in Ustilago maydis. Mol. Gen. Genet. 260:193-198.

Krüger, J., Loubradou, G., Wanner, G., Regenfelder, E., Feldbrugge, M., and Kahmann, R. 2000. Activation of the cAMP pathway in Ustilago maydis reduces fungal proliferation and teliospore formation in plant tumors. Mol. Plant-Microbe Interact. 13:1034-1040.

Kusch, G., and Schauz, K. 1989. Light and electron microscopic studies of chlamydospore development in Ustilago maydis. Cryptogamic Bot. $1: 230-235$.

Lengeler, K. B., Davidson, R. C., D’Souza, C., Harashima, T., Shen, W. C., Wang, P., Pan, X., Waugh, M., and Heitman, J. 2000. Signal trans- 
duction cascades regulating fungal development and virulence. Microbiol. Mol. Biol. Rev. 64:746-785.

Levine, M., and Davidson, E. H. 2005. Gene regulatory networks for development. Proc. Natl. Acad. Sci. U.S.A. 102:4936-4942.

Liu, H. 2002. Co-regulation of pathogenesis with dimorphism and phenotypic switching in Candida albicans, a commensal and a pathogen. Int. J. Med. Microbiol. 292:299-311.

Lo, H. J., Kohler, J. R., DiDomenico, B., Loebenberg, D., Cacciapuoti, A., and Fink, G. R. 1997. Nonfilamentous Candida albicans mutants are avirulent. Cell 90:939-949.

Loubradou, G., Brachmann, A., Feldbrugge, M., and Kahmann, R. 2001. A homologue of the transcriptional repressor Ssn6p antagonizes cAMP signalling in Ustilago maydis. Mol. Microbiol. 40:719-730.

Luttrell, E. S. 1987. Relations of hyphae to host cells in smut galls caused by species of Tilletia, Tolyposporium, and Ustilago. Can. J. Bot.-Rev. Can. Bot. 65:2581-2591.

Mayorga, M. E., and Gold, S. E. 1999. A MAP kinase encoded by the $u b c 3$ gene of Ustilago maydis is required for filamentous growth and full virulence. Mol. Microbiol. 34:485-497.

Mayorga, M. E., and Gold, S. E. 2001. The $u b c 2$ gene of Ustilago maydis encodes a putative novel adaptor protein required for filamentous growth, pheromone response and virulence. Mol. Microbiol. 41:13651379.

Miller, K. Y., Toennis, T. M., Adams, T. M., and Miller, B. L. 1991. Isolation and transcriptional characterization of a transcriptional modifier: the Aspergillus nidulans stunted (stuA) gene. Mol. Gen. Genet. 227:285-292.

Miller, K. Y., Wu, J., and Miller, B. L. 1992. StuA is required for cell pattern formation in Aspergillus. Genes Dev. 6:1770-1782.

Müller, P., Aichinger, C., Feldbrugge, M., and Kahmann, R. 1999. The MAP kinase kpp2 regulates mating and pathogenic development in Ustilago maydis. Mol. Microbiol. 34:1007-1017.

Noffz, C. S., Liedschulte, V., Lengeler, K., and Ernst, J. F. 2008. Functional mapping of the Candida albicans Efg1 regulator. Eukaryot. Cell 7:881-893.

Ohara, T., and Tsuge, T. 2004. FoSTUA, encoding a basic helix-loop-helix protein, differentially regulates development of three kinds of asexual spores, macroconidia, microconidia, and chlamydospores, in the fungal plant pathogen Fusarium oxysporum. Eukaryot. Cell 3:1412-1422.

Pan, X., and Heitman, J. 2000. Sok2 regulates yeast pseudohyphal differentiation via a transcription factor cascade that regulates cell-cell adhesion. Mol. Cell Biol. 20:8364-8372.

Quadbeck-Seeger, C., Wanner, G., Huber, S., Kahmann, R., and Kamper, J. 2000. A protein with similarity to the human retinoblastoma binding protein 2 acts specifically as a repressor for genes regulated by the $b$ mating type locus in Ustilago maydis. Mol. Microbiol. 38:154-166.

Sambrook, J., Fritsch, E. F., and Maniatis, T. 1989. Molecular Cloning: A Laboratory Manual, 2nd ed. Cold Spring Harbor Laboratory Press, Cold Spring Harbor, NY, U.S.A.

Scherer, M., Wei, H., Liese, R., and Fischer, R. 2002. Aspergillus nidulans catalase-peroxidase gene (cpeA) is transcriptionally induced during sexual development through the transcription factor StuA. Eukaryot. Cell 1:725-735.

Shenhar, G., and Kassir, Y. 2001. A positive regulator of mitosis, Sok2, functions as a negative regulator of meiosis in Saccharomyces cerevisiae. Mol. Cell Biol. 21:1603-1612.

Sheppard, D. C., Doedt, T., Chiang, L. Y., Kim, H. S., Chen, D., Nierman, W. C., and Filler, S. G. 2005. The Aspergillus fumigatus StuA protein governs the up-regulation of a discrete transcriptional program during the acquisition of developmental competence. Mol. Biol. Cell 16:58665879 .

Snetselaar, K. M., and Mims, C. W. 1992. Sporidial fusion and infection of maize seedlings by the smut fungus Ustilago maydis. Mycologia 84:193-203.

Snetselaar, K. M., and Mims, C. W. 1994. Light and electron-microscopy of Ustilago maydis hyphae in maize. Mycol. Res. 98:347-355.

Sohn, K., Urban, C., Brunner, H., and Rupp, S. 2003. EFG1 is a major regulator of cell wall dynamics in Candida albicans as revealed by DNA microarrays. Mol. Microbiol. 47:89-102.

Sonneborn, A., Bockmuhl, D. P., and Ernst, J. F. 1999. Chlamydospore formation in Candida albicans requires the Efg1p morphogenetic regulator. Infect. Immun. 67:5514-5517.

Sonneborn, A., Bockmuhl, D. P., Gerads, M., Kurpanek, K., Sanglard, D., and Ernst, J. F. 2000. Protein kinase A encoded by TPK2 regulates dimorphism of Candida albicans. Mol. Microbiol. 35:386-396.

Spellig, T., Bölker, M., Lottspeich, F., Frank, R. W., and Kahmann, R. 1994. Pheromones trigger filamentous growth in Ustilago maydis. EMBO (Eur. Mol. Biol. Organ.) J. 13:1620-1627.

Srikantha, T., and Soll, D. R. 1993. A white-specific gene in the whiteopaque switching system of Candida albicans. Gene 131:53-60.

Srikantha, T., Tsai, L. K., and Soll, D. R. 1997. The WH11 gene of Candida albicans is regulated in two distinct developmental programs through the same transcription activation sequences. J. Bacteriol. 179:3837-3844.

Stoldt, V. R., Sonneborn, A., Leuker, C. E., and Ernst, J. F. 1997. Efg1p, an essential regulator of morphogenesis of the human pathogen Candida albicans, is a member of a conserved class of bHLH proteins regulating morphogenetic processes in fungi. EMBO (Eur. Mol. Biol. Organ.) J. 16:1982-1991.

Tebarth, B., Doedt, T., Krishnamurthy, S., Weide, M., Monterola, F., Dominguez, A., and Ernst, J. F. 2003. Adaptation of the Efg1p morphogenetic pathway in Candida albicans by negative autoregulation and PKA-dependent repression of the EFG1 gene. J. Mol. Biol. 329:949962.

Tong, X., Zhang, X., Plummer, K. M., Stowell, K. M., Sullivan, P. A., and Farley, P., C. 2007. GcSTUA, an APSES transcription factor, is required for generation of appressorial turgor pressure and full pathogenicity of Glomerella cingulata. Mol. Plant-Microbe Interact. 20:1102-1111.

Tsukuda, T., Carleton, S., Fotheringham, S., and Holloman, W. K. 1988. Isolation and characterization of an autonomously replicating sequence from Ustilago maydis. Mol. Cell Biol. 8:3703-3709.

Wang, Q., and Szaniszlo, P. J. 2007. WdStuAp, and APSES transcription factor, is a regulator of yeast-hyphal transitions in Wangiella (Exophiala) dermatitidis. Eukaryot. Cell 6:1595-1605.

Ward, M. P., Gimeno, C. J., Fink, G. R., and Garrett, S. 1995. SOK2 may regulate cyclic AMP-dependent protein kinase-stimulated growth and pseudohyphal development by repressing transcription. Mol. Cell. Biol. 15:6854-6863

Wittenberg, C., and Reed, S. I. 2005. Cell cycle-dependent transcription in yeast: promoters, transcription factors, and transcriptomes. Oncogene 24:2746-2755.

Wu, J., and Miller, B. L. 1997. Aspergillus asexual reproduction and sexual reproduction are differentially affected by transcriptional and translational mechanisms regulating stunted gene expression. Mol. Cell. Biol. 17:6191-6201.

Xu, J., Saunders, C. W., Hu, P., Grant, R. A., Boekhourt, T., Kuramae, E. E., Kronstad, J. W., DeAngelis, Y. M., Reeder, N. L., Johnstone, K. R., Leland M., Fieno, A. M., Begley, W. M., Sun, Y., Lacey, M. P., Chaudhary, T., Keough, T., Chu, L., Sears, R., Yuan, B., and Dawson Jr. T., L. 2007. Dandruff-associated Malassezia genomes reveal convergent and divergent virulence traits shared with plant and human fungal pathogens. Proc. Natl. Acad. Sci. U.S.A 104.:18730-18735.

Yee, A. R., and Kronstad, J. W. 1993. Construction of chimeric alleles with altered specificity at the $b$ incompatibility locus of Ustilago maydis. Proc. Natl. Acad. Sci. U.S.A. 90:664-668.

Yee, A. R., and Kronstad, J. W. 1998. Dual sets of chimeric alleles identify specificity sequences for the $\mathrm{bE}$ and $\mathrm{bW}$ mating and pathogenicity genes of Ustilago maydis. Mol. Cell. Biol. 18:221-232.

\section{AUTHOR-RECOMMENDED INTERNET RESOURCE}

The Munich Information Center for Protein Sequences Ustilago maydis genome database: mips.gsf.de/genre/proj/ustilago 